\title{
Hepatic patatin-like phospholipase domain-containing protein 3 sequence, single nucleotide polymorphism presence, protein confirmation, and responsiveness to energy balance in dairy cows
}

\author{
Christine C. McCann, ${ }^{*}$ Molly E. Viner, ${ }^{*}$ Shawn S. Donkin, $†$ and H. M. White $\ddagger^{1}$ \\ *Department of Animal Science, University of Connecticut, Storrs 06269 \\ †Department of Animal Sciences, Purdue University, West Lafayette, IN 47907 \\ ‡Department of Dairy Science, University of Wisconsin, Madison 53706
}

\begin{abstract}
Patatin-like phospholipase domain-containing protein 3 (PNPLA3), commonly known as adiponutrin, is part of a novel subfamily of triglyceride lipase enzymes with potential effects on triglyceride metabolism in adipose and hepatic tissues. The predicted bovine PNPLA3 sequence has been identified, but expression of the gene had not been examined. The objectives of this study were to confirm the predicted bovine PNPLA3 gene sequence, determine expression of the bovine PNPLA3 gene in response to whole-animal energy balance, identify single nucleotide polymorphisms present in dairy cows, and verify the presence of the protein in the liver. Using liver biopsy samples collected from cows at +28 $\mathrm{d}$ relative to calving (DRTC), RNA was isolated and used to generate a cDNA template for amplification of the entire predicted coding sequence of PNPLA3 via PCR. To determine if energy balance alters the expression of PNPLA3, RNA was isolated and mRNA expression quantified in liver samples from mid-lactation cows after a 5 - $\mathrm{d}$ ad libitum period $(\mathrm{n}=5)$ and after a subsequent 5 -d $50 \%$ feed restriction period $(\mathrm{n}=5)$, and in samples collected from cows at $-14,+1,+14$, and +28 DRTC $(\mathrm{n}=16)$. The presence of PNPLA3 protein was detected by Western blot in liver protein samples collected at +28 DRTC. Expression of hepatic PNPLA3 was decreased after a period of feed restriction (8.14 vs. $1.08 \pm 2.17$ arbitrary units, ad libitum vs. fasted). Expression of PNPLA3 mRNA was decreased at +1 and +14 DRTC compared with -14 DRTC $(23.35,7.28,10.17$, and $14.5 \pm 4.9$ arbitrary units, -14 , $+1,+14$, and +28 DRTC, respectively). The presence of PNPLA3 protein was detected as a $55-\mathrm{kDa}$ band in hepatic protein isolations from liver tissue collected at +28 DRTC. These data confirm the presence and sequence of the bovine hepatic PNPLA3 gene and single
\end{abstract}

Received January 6, 2014

Accepted May 2, 2014.

${ }^{1}$ Corresponding author: hwhite4@wisc.edu nucleotide polymorphisms. Furthermore, these data indicate responsiveness of bovine hepatic PNPLA3 to energy balance.

Key words: phospholipase domain-containing protein 3 (PNPLA3), adiponutrin, lipase, transition cow

\section{INTRODUCTION}

Patatin-like phospholipase domain-containing protein 3 (PNPLA3), also known as adiponutrin, is a 441-AA, membrane-associated protein, found in both adipose tissue and the liver (Moldes et al., 2006). Although the metabolic role of PNPLA3 is not fully understood, evidence of regulation supports a role of PNPLA3 in lipid storage and deposition in adipose tissue and the lipolysis of triglycerides in hepatocytes (Browning et al., 2010; Chen et al., 2010). The expression of PNPLA3 mRNA in adipose and hepatic tissue is suppressed during fasting in rodents and humans, and is increased by subsequent refeeding with a high-protein or high-carbohydrate diet (Hoekstra et al., 2010; Huang et al., 2010; Oliver et al., 2012). Responsiveness of adipose PNPLA3 to the fed and fasted states in rodents is mediated by insulin (Johansson et al., 2006; Kershaw et al., 2006). Additionally, PNPLA3 has been demonstrated to be transcriptionally and posttranslationally regulated by FA in rodent and human hepatocytes (Huang et al., 2010).

The importance of PNPLA3 in hepatic lipid metabolism has been highlighted by recent correlations between presence of an inactivating PNPLA3 SNP (I148M; rs738409) and central adiposity and nonalcoholic fatty liver disease (NAFLD; Rotman et al., 2010; Speliotes et al., 2010; Corbin et al., 2013). Presence of the SNP increases liver lipid content as well as the onset and progression of NAFLD in both children and adults (Browning et al., 2010; Speliotes et al., 2010; Corbin et al., 2013). Correlations between protein inactivation by SNP presence and disease onset and progression has led to use of this SNP as a marker for NAFLD predisposition (Corbin et al., 2013). 
The putative bovine PNPLA3 gene [National Center for Biotechnology Information (NCBI) Entrez gene ID: 786474] was identified by the Bovine Genome Project and is $80 \%$ homologous to the human PNPLA3 gene (Zimin et al., 2009). The extensive homology between bovine and human PNPLA3, and the role of PNPLA3 in lipid metabolism of other species, suggests that PNPLA3 may play a role in lipid metabolism in dairy cattle. Expression of PNPLA3 was undetectable in bovine subcutaneous adipose tissue (Ji et al., 2012) but noted to change in hepatic tissue across the peripartum period (Khan et al., 2014). Expression of bovine hepatic PNPLA3 mRNA at parturition and protein abundance in bovine, have not been previously reported. Microarray analysis of liver tissue from feed restricted beef steers indicated that PNPLA3 was detected and increased on the first day of feed realimentation, but was not further examined (Connor et al., 2010). We hypothesize that PNPLA3 is present in dairy cattle and that expression will be decreased during negative energy balance as a result of feed restriction or calving. The objectives of this study were to confirm the predicted bovine $P N P L A 3$ gene sequence, determine expression of the bovine PNPLA3 gene in response to whole-animal energy balance, identify SNP present in dairy cows, and verify the hepatic protein presence.

\section{MATERIALS AND METHODS}

\section{Animal Handling and Sample Collection}

Feed Restriction and Transition Cow Experiments. Liver biopsy samples from feed-restricted and transition cows were collected during experiments conducted at Purdue University (West Lafayette, IN). Full details regarding experimental design, methods, animal performance, and plasma NEFA have been reported previously (Carvalho et al., 2011; White et al., 2011a). Liver biopsy samples collected at $-14,+1,+14,+28$ d relative to calving (DRTC) in control-fed transition cows, and in mid-lactation cows after $5 \mathrm{~d}$ of ad libitum access to feed or $50 \%$ feed restriction were collected for isolation of RNA. Animal use and animal-handling protocols were approved by the Purdue University Animal Care and Use Committee.

Postcalving Cow Experiment. Seventeen multiparous Holstein and Jersey cows in early lactation from the University of Connecticut (Storrs) dairy herd were housed in group freestalls at the Kellogg Dairy Center and allowed ad libitum access to diets formulated to meet or exceed the NRC (2001) guidelines for a $650-\mathrm{kg}$ early-lactation cow. Cows were milked 3 times daily at approximately 0500,1300 , and $2100 \mathrm{~h}$, and individual milk yield was recorded electronically at each milking.
Liver biopsy samples were collected at +28 DRTC via percutaneous biopsy, frozen in liquid nitrogen, and stored at $-80^{\circ} \mathrm{C}$ for subsequent sequence, SNP, and protein analysis. Animal-use and -handling protocols were approved by the University of Connecticut Animal Care and Use Committee.

\section{Gene Expression Analysis}

Expression of PNPLA3 mRNA was examined in samples collected during the feed-restriction $(\mathrm{n}=13)$ and transition-cow $(\mathrm{n}=16)$ experiments. Total RNA was isolated using TRIzol reagent (Invitrogen Corp., Carlsbad, CA) and quantified by absorbance at 260 nm using an ND-1000 spectrophotometer (NanoDrop Technologies Inc., Wilmington, DE). The ratio of absorbance at 260 and $280 \mathrm{~nm}$ was between 1.95 and 2.00 for all samples. The integrity of the samples was also determined using a ratio of $28 \mathrm{~S}$ to $18 \mathrm{~S}$ rRNA after

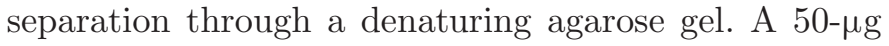
RNA pool was formed by combining equal quantities of total RNA from all cows and for all sampling times for the transition-cow study and was treated with DNase I and further purified using an RNeasy Mini Kit (Qiagen Inc., Thousand Oaks, CA). Cleaned samples (2 $\mu \mathrm{g})$ were reverse transcribed using an Omniscript reversetranscription kit (Qiagen Inc.), oligomeric deoxythymine (oligo-dT; Qiagen Inc.), and random decamers (Ambion Inc., Foster City, CA).

Abundance of PNPLA3 mRNA was determined by real-time quantitative PCR and normalized to $18 \mathrm{~S}$ as described previously (White et al., 2011a, 2012) in samples collected from feed-restricted and transition cows. Primers were as follows: PNPLA3: AGACATGCCCGGCGACATCCA (forward) and CAGCAGGTACACTGGGAC CTCTGA (reverse); 18S (Bos taurus gene number 493779): ACCCATTCGAACGTCTG CCCTATT (forward) and TCCTTGGATTGTGGTAGCCGTTTCT (reverse). Reactions were as follows: 1 cycle at $95^{\circ} \mathrm{C}$ for $10 \mathrm{~min} ; 40$ cycles at $95^{\circ} \mathrm{C}$ for $30 \mathrm{~s}$, $55^{\circ} \mathrm{C}$ for $1 \mathrm{~min}$, and $72^{\circ} \mathrm{C}$ for $30 \mathrm{~s}$; and 1 cycle at $95^{\circ} \mathrm{C}$ for $1 \mathrm{~min}, 55^{\circ} \mathrm{C}$ for $30 \mathrm{~s}$, and $95^{\circ} \mathrm{C}$ for $30 \mathrm{~s}$. Only reaction efficiencies that were between 90 and $110 \%$ based on standard curve of pooled samples were used for further analysis. All samples, standards, and controls were analyzed in triplicate, and mean values normalized to $18 \mathrm{~S}$ mRNA abundance within each sample. The use of $18 \mathrm{~S}$ for data normalization was verified by the lack of an effect of treatment or DRTC on the threshold cycle or quantity, and differences in threshold cycle values of less than 1 between treatment groups, indicating a lack of bias by the housekeeping gene. Although methods of normalization and selection of reference genes vary, $18 \mathrm{~S}$ is consistently expressed in hepatic tissue during peri- 
ods of physiological regulation, lipid accumulation, and toxicity in the liver (Boujedidi et al., 2012; Lardizábal et al., 2012; Matoušková et al., 2014).

\section{Sequence Analysis}

Total RNA was isolated from liver biopsy samples collected during the post-calving experiment $(\mathrm{n}=17)$ using TRIzol reagent (Ambion Inc., Life Technologies) and quantified by absorbance at $260 \mathrm{~nm}$ using a ND1000 (NanoDrop Technologies Inc.). The ratio of absorbance at 260 and $280 \mathrm{~nm}$ was between 1.95 and 2.00 for all samples. The integrity of the samples was also determined using the ratio of $28 \mathrm{~S}$ to $18 \mathrm{~S}$ rRNA after separation through a denaturing agarose gel. Samples were reverse transcribed using the iTaq reverse-transcription kit to generate cDNA (Bio-Rad Laboratories Inc., Hercules, CA). A series of primer pairs were designed (NBCI Primer-Blast, Bethesda, MD) based on the predicted 1,351-bp bovine PNPLA3 coding region (XM_001253780). Primers were as follows, listed with respective primer-pair-specific annealing temperatures and extension times: CCCAACCTCCCGCCGCTATG (forward) and CCGGGTGAGGTCCATGAGGAT (reverse), $59.6^{\circ} \mathrm{C}, 15 \mathrm{~s}$; GACGTTGCAGATCCTCATGG (forward) and ACTCCTCCGTCCACGTATCG (reverse), $54.0^{\circ} \mathrm{C}, 15 \mathrm{~s} ;$ TGTCGGATTTTCATTCCAAAGAC (forward) and GGTAAGAAGTTGCAAATCCTGTTT (reverse), $56.9^{\circ} \mathrm{C}, 21 \mathrm{~s} ; \mathrm{CC}-$ GAGCTCAGCATGG CACTGAG (forward) and CTGGGTGGGTGTCCGGGTCC (reverse), $59.6^{\circ} \mathrm{C}$, $16 \mathrm{~s}$; and AAACAGGATTTGCAACTTCTTACC (forward) and TTTTCAGCTCTGGCCTCTG (reverse), $57.5^{\circ} \mathrm{C}, 16 \mathrm{~s}$. Regions of cDNA were amplified by PCR (Bio-Rad C1000 Touch Thermal Cycler; Bio-Rad Laboratories Inc.) using a Fast Cycling PCR kit (Qiagen Inc., Valencia, CA) and the following thermocycling conditions: 1 cycle at $95^{\circ} \mathrm{C}$ for $5 \mathrm{~min} ; 40$ cycles of the following: $96^{\circ} \mathrm{C}$ for $5 \mathrm{~s}$, primer-specific annealing temperature for $5 \mathrm{~s}, 68^{\circ} \mathrm{C}$ for the primer-specific extension time; and 1 cycle at $72^{\circ} \mathrm{C}$ for $1 \mathrm{~min}$.

After amplification, cloned products were visualized via electrophoresis for confirmation of predicted size and purified (Qiagen Inc., Valencia, CA). A volume containing $30 \mathrm{ng}$ of purified product was then prepared for sequencing using BigDye Terminator Cycle Sequencing Kit (version 3; Applied Biosystems Inc., Carlsbad, CA). The BigDye sequencing PCR added a UV label to the cloned product and produced unidirectional synthesis of DNA that terminated at different lengths by using only one half of a PCR primer pair. Ethanol precipitation purified and concentrated the DNA, which was resuspended in Hi-Di formamide (Applied Biosystems Inc.) before sequencing. Regions were sequenced with both forward and reverse primers using an ABI 3130 Sequencer (Applied Biosystems Inc.) housed at the Center for Applied Genomic Technology at the University of Connecticut.

Sequences were exported into Chromas software (Technelysium Pty Ltd., Southport, Queensland, Australia) for sequence analysis and base verification. Verified sequences were aligned to the putative bovine PNPLA3 Gene, using the NCBI BLAST algorithm (http://blast.ncbi.nlm.nih.gov/Blast.cgi), and were compared between cows for sequence overlap for consistency and SNP identification. Single nucleotide polymorphisms were identified as single-base deviations from the putative sequence and cross-referenced with the SNP putatively identified during the Bovine Genome Project (Zimin et al., 2009).

\section{Protein Validation}

Protein was extracted from the liver samples collected from 7 cows at +28 DRTC from the University of Connecticut herd using a total protein extraction kit (Millipore Corp., Billerica, MA). The protein concentration was determined by BCA protein assay (Pierce Biotechnology Inc., Rockford, IL). A volume containing $50 \mu \mathrm{g}$ of protein from each cow and a Precision Plus Western C standard with Strep-Tactin horseradish peroxidase (HRP) conjugate secondary antibody (Bio-Rad Laboratories Inc.) was run on a 4 to $16 \%$ gradient gel (Bio-Rad Laboratories Inc.) at $60 \mathrm{~V}$ for $20 \mathrm{~min}$, and then at $100 \mathrm{~V}$ for $1.5 \mathrm{~h}$. The gel was transferred to a polyvinylidene fluoride (PVDF) membrane by wet transfer for $1.5 \mathrm{~h}$ at $250 \mathrm{~mA}$. The membrane was briefly stained with Ponceau stain to visualize proteins and verify transfer. A blocking solution of $1 \times$ Tris-buffered saline (TBS)-Tween and 5\% nonfat dry milk was prepared and the membrane was incubated in the blocking solution overnight in a $5^{\circ} \mathrm{C}$ cold room before adding the primary antibody. Rabbit polyclonal antibody to PNPLA3 (ab81874; Abcam PLC, Cambridge, MA) was diluted (1:500) in the blocking solution and the membrane was incubated at room temperature (RT) for 1 to $2 \mathrm{~h}$. The membrane was removed and washed in $1 \times$ TBS-Tween 3 times, for $5 \mathrm{~m}$ each. Goat polyclonal secondary antibody to rabbit IgG-HRP (ab97080; Abcam PLC) was diluted $(1: 5,000)$ in the blocking solution and the membrane was incubated at RT for $1 \mathrm{~h}$. The membrane was washed 4 times in TBS-Tween for 5 min each time. The protein was detected using Super Signal (Thermo Scientific, Hanover Park, IL) and visualized by a ChemiDoc (Bio-Rad Laboratories Inc.). Qualitative Western blot analysis was used to identify the presence of PNPLA3 antibody-binding protein in the bovine liver. 


\begin{tabular}{|c|c|c|c|c|c|}
\hline $\operatorname{cgccggctgc}$ & ggcttcctgt & gcgtctacta & cgtcggggtg & accegctgec & tgagcgagca \\
\hline & ctcetccgec & aagtgcaaaa & gttcttcgge & gcctcgtcgg & \\
\hline gcgecttc & ttcctctccg & ggatcccgct & ggaccagacg & ttgcagatcc & tcatggacct \\
\hline acceggagc & gccagaagcc & agaaattcgg & gatcgtccac & ccaggcttca & gtttgagcaa \\
\hline :acacccga & gacggtctcc & agagacacct & ccctgacaac & gtccaccagc & ttgtctcggg \\
\hline agatggtc & gtctcgctta & ccagagtgtc & ggacggaaaa & aacgtgctgg & tgtcggatt \\
\hline attccaaa & gacgaagtcg & tggacgcctt & gtgctgttcc & tgctacgtcc & ctttcatctg \\
\hline ggctggatc & $\operatorname{ccccct} t \operatorname{cct}$ & tcagaggcgt & glegatacgtg & gacggaggag & taactgatat \\
\hline atgccettc & gttgattcca & aaaagaccat & cactgtgtcc & cccttctatg & gggagagcga \\
\hline atctgeccc & aaagtcaagt & ccacgltctt & tcttaacgaa & gggttcacca & agctcaacat \\
\hline cagttctgc & acagagaacc & tctactgat & gttccggtcg & ctgttaatgc & tggatgtcaa \\
\hline atgcttgga & gagctgtgcc & ttcaaggata & tgtggacgcg & ctcaggttct & tggagaaga \\
\hline dggcatccgt & gaggggcccc & atccgtgcct & gagcgcggcc & cccgcagagg & cagagtcg \\
\hline gdccaggagc & ctggagcetc & ttctgggtgt & ggccacgtgg & gaggcggggc & ctgaggcagt \\
\hline cgagctgctg & gaccacctgc & gectccgcgt & gctgacctgg & gacgagggcg & tcctggaga \\
\hline tgtcgecc & gagctcagca & tggcactgag & gaaggcagtc & agaaacccag & atgggtacag \\
\hline aaacaggatt & tgcaacttct & talccagttaa & gatcatgtcc & tacgtgatgc & tgccetgtac \\
\hline $\operatorname{ctg} \operatorname{cccgtg}$ & gagtctgcca & tcgctgtggt & ccagagactg & gtgacgtggc & ttccagaca \\
\hline G & atccagtggc & tgtggtcggc & cacctcclcac & gtgtgttctc & aagccatgs \\
\hline gegtctgctc & ccogettcca & gafcccaat & cccagcaagc & ggccaacggc & cttectcona \\
\hline aaccaggac & $\begin{array}{l}\text { actgtgggcg } \\
\text { tcccqcaqaq }\end{array}$ & tctgctgggct & ctctgctcct & ccgaggaccc & \\
\hline
\end{tabular}

Figure 1. The confirmed coding region sequence of bovine patatin-like phospholipase domain-containing protein 3 (PNPLA3; XM_001253780). The region contains 9 exons, with exon junctions indicated by vertical lines $(\mid)$.

\section{Statistical Analysis}

Data were analyzed using PROC MIXED SAS (version 9.3; SAS Institute Inc., Cary, NC). Data were interrogated for normality of error variances, and all data met the assumptions of normal, independent, and random distribution. A compound symmetry covariance structure was used to evaluate variables. Analysis of gene expression from the feed-restriction experiment accounted for the fixed effects of treatment (control vs. feed restricted). Analysis of gene expression from the transition-cow experiment was analyzed with repeated measures by DRTC. All analyses accounted for the random effect of cow within treatment or time point. Means were significantly different when $P<0.05$ and Tukey-Kramer studentized adjustments were used for means separation. Data are presented as means \pm standard error. Potential correlations between adiponutrin expression and plasma NEFA concentration in combined data from both feed-restricted and transition cows was determined using PROC CORR of SAS (version 9.3).

\section{RESULTS}

\section{Transcript Analysis}

Amplified regions of the bovine PNPLA3 coding region were successfully sequenced and overlapped for 16 cows. Individual cow sequences were compared with the predicted sequence of bovine PNPLA3, as produced by the Bovine Genome Project (Zimin et al., 2009) using the NCBI BLAST algorithm. Overall, the predicted sequence was confirmed to have $92 \%$ homology with the sequence from the current experiment (Figure 1).

Expression of hepatic PNPLA3 mRNA was decreased $(P<0.05)$ after feed restriction (Figure 2). Hepatic PNPLA3 mRNA expression was also decreased $(P<$ $0.05)$ at +1 and +14 DRTC compared with -14 DRTC (Figure 3). Hepatic mRNA expression of PNPLA3 was negatively correlated $(\mathrm{r}=-0.33 ; P<0.05)$ with plasma NEFA concentration.

\section{SNP Identification}

Following the confirmation of the PNPLA3 sequence, individual cow sequences were interrogated for presence of SNP. Of the 84 putative SNP identified during sequencing of the predicted $P N P L A 3$ gene region of the bovine genome (Zimin et al., 2009), 9 SNP were within the coding region. Although the data set is small, initial prevalences of SNP are provided, as are the nucleotide and AA mutation. Sequences from the current experiment verified the presence of 7 SNP. Synonymous mutations at rs110468637 (C to T, Asn, N211N), rs110644674 (A to G, Leu, L237L), and rs109112903 (C to T, Asn, N252N) were confirmed. Prevalences of these SNP in this data set were each $100 \%$. Four nonsynonymous 


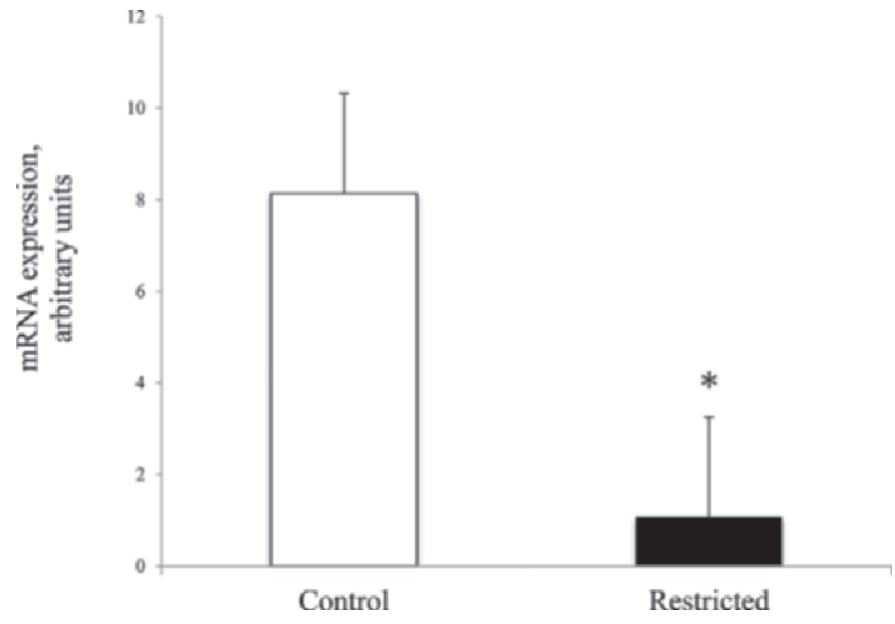

Figure 2. Expression of hepatic patatin-like phospholipase domaincontaining protein 3 (PNPLA3) mRNA in mid-lactation cows allowed ad libitum access to feed (control; open bar) or $50 \%$ feed restriction (restricted; solid bar) for $5 \mathrm{~d}(\mathrm{n}=10)$. The asterisk indicates a difference $(P<0.05)$. Error bars represent the SE.

mutations were confirmed. At rs109485255 (C to T), the SNP caused a codon change of CGG to TGG, resulting in an Arg-to-Trp AA mutation (R429W), with the $\mathrm{T}$ mutation detected in $25 \%$ of cows genotyped in this study. At rs109117844 (C to T), a codon change from GCG to GTG resulted in an AA mutation of Ala to Val (A392V), with the $\mathrm{T}$ mutation detected in $8 \%$ of cows genotyped. A mutation at rs110179928 (A to $\mathrm{G}$ ) resulted in a codon change from GGC to AGC and shifted the AA from Gly to Ser (G374S), with the G mutation detected in $8 \%$ of cows genotyped. Similarly, a Gly-to-Ser (G406S) mutation observed at rs109702287 (A to $\mathrm{G}$ ) resulted from a GGC-to-AGC codon change, with the $\mathrm{G}$ mutation detected in $10 \%$ of cows genotyped. Two nonsynonymous SNP [rs110921128 (A to T, L313Q) and rs110528165 (C to T, S388F)] identified previously were not confirmed in sequences from these cows. Figure 4 summarizes verified SNP in the bovine $P N P L A 3$ gene and depicts a visual comparison to the human PNPLA3 gene (Romeo et al., 2008).

\section{Protein Validation}

Western blotting was used to verify the presence of bovine PNPLA3 and corresponded to a $55-\mathrm{kDa}$, 441AA protein that was similar to human PNPLA3 in all 7 cows examined, as shown in the representative Western blot (Figure 5).

\section{DISCUSSION}

The putative bovine PNPLA3 was determined by automated computational analysis during the Bovine Genome Project (Zimin et al., 2009) but had not yet been confirmed. Using sequence alignment in the NCBI BLAST algorithm, the hepatic PNPLA3 sequence determined in the current experiment was aligned to the predicted PNPLA3 with a high degree of homology, confirming the 1,351-bp sequence.

In the current work, regulation of PNPLA3 mRNA was examined in 2 models of negative energy balance: feed restriction and the transition to lactation period. Examining gene expression in both states of negative energy balance can aid in determining whether regulation of a gene is due to the changes associated with negative energy balance itself (i.e., increased plasma NEFA concentration) or due to factors associated with the homeorhetic response to calving. Expression of hepatic PNPLA3 mRNA was decreased 7 -fold in mid-lactation cows after a period of feed restriction compared with control cows given ad libitum access to feed. Expression of hepatic PNPLA3 mRNA was also decreased 3.2-fold at calving, a period of voluntary feed intake depression in dairy cows. This decreased expression of PNPLA3 mRNA after imposed feed restriction or naturally occurring feed intake depression is similar to decreased expression observed in mice and humans after fasting (Lake et al., 2005; Hoekstra et al., 2010; Huang et al., 2010). It is apparent in the current data that PNPLA3 expression is decreased during negative energy balance, whether the energy deficit is due to the transition to lactation or due to feed restriction. These findings agree with the identification of a 2 -fold increase in hepatic PNPLA3 in beef steers in microarray analysis of live tissue collected on the first day of feed realimentation after 60 to $70 \%$ feed restriction (Connor et al., 2010). In a study examining the effects

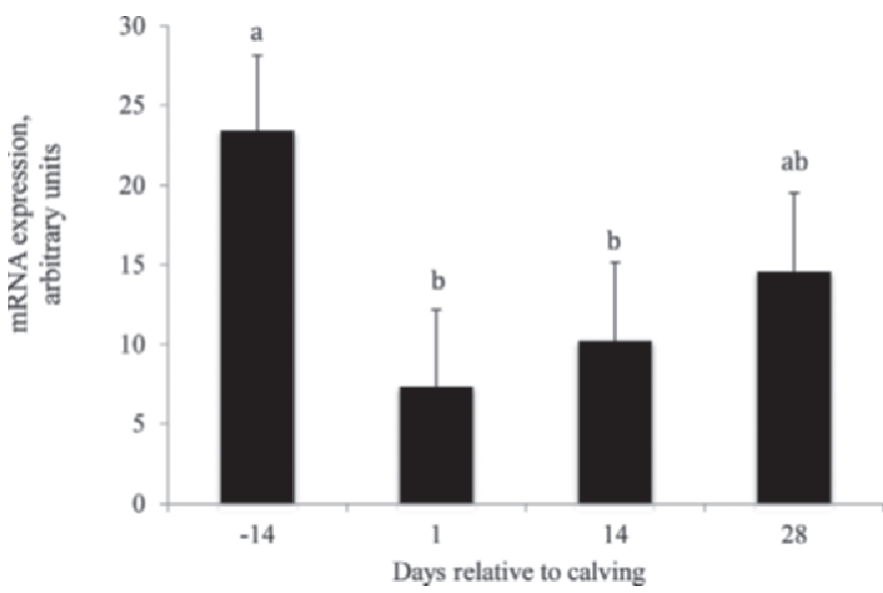

Figure 3. Expression of hepatic patatin-like phospholipase domain-containing protein 3 (PNPLA3) mRNA during the transition to lactation in liver biopsy samples from dairy cattle $(\mathrm{n}=16)$. Means with different letters $(\mathrm{a}$ and $\mathrm{b})$ are significantly different $(P<0.05)$. Error bars represent the SE. 
1

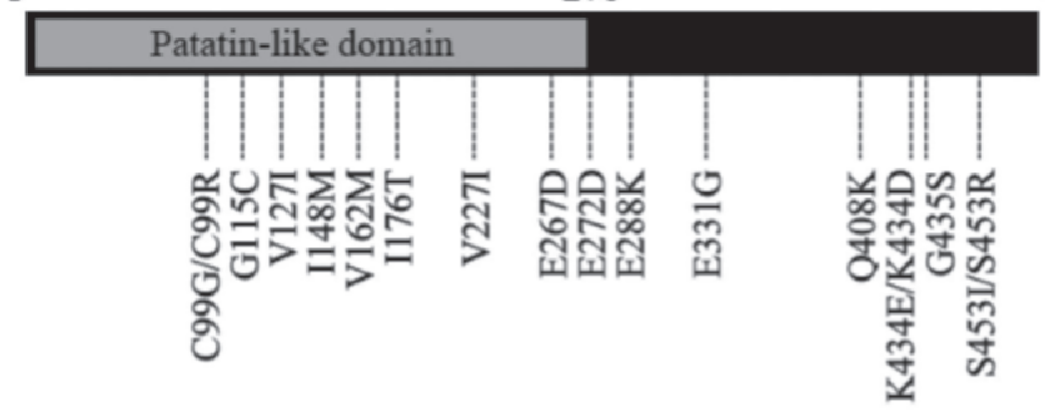

1
276 481
Human PNPLA3

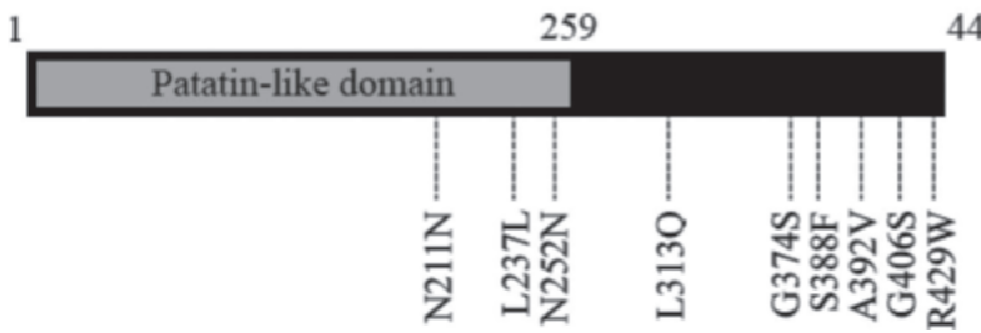

Bovine PNPLA3

Figure 4. Comparison of human patatin-like phospholipase domain-containing protein 3 (PNPLA3; NM_025225; Romeo et al., 2008) and bovine PNPLA3 (coding region XM_001253780), highlighting identified SNP. The SNP nomenclature indicates wild-type AA, AA number, and mutant AA. Bovine PNPLA3 SNP N211N, L237L, N252N, G374S, A392V, G406S, and R429W were identified during the Bovine Genome Project (Zimin et al., 2009) and confirmed during the current research; SNP L313Q and S388F (Zimin et al., 2009) were not confirmed within the identified SNP in the current samples.

of prepartum overfeeding, no difference was observed in PNPLA3 expression during the peripartum period when cows were overfed prepartum (Khan et al., 2014). Samples were not collected at -7 or +1 DRTC, so it is unclear when the PNPLA3 expression nadir was in those samples; however, PNPLA3 expression was greatest at 7 or 14 DRTC (control and overfed, respectively; Khan et al., 2014), which would represent a refeeding period relative to the time of parturition. Together, these data suggest that PNPLA3 is likely responsive to feed restriction, but not overnutrition.

Several experiments have demonstrated that PNPLA3 is responsive to energy balance in rodents and humans, likely through FA mediation (Liu et al., 2004; Hoekstra et al., 2010; Huang et al., 2010; Oliver et al., 2012). Regulation during the fed and fasted states differs in monogastric and ruminant animals; however, regulation of human and rodent PNPLA3 during feed restriction has been attributed to changes in circulating FA. Mice overexpressing SREBP-1a, SREBP-1c, and SREBP-2 had increased hepatic PNPLA3 mRNA expression, indicating a role for transcriptional regulation (Huang et al., 2010). Exposure of cells to SFA, MUFA, or PUFA, but not the very long-chain PUFA, increased PNPLA3 protein abundance (Huang et al., 2010). Additionally, exposure to oleate increased the half-life of the PNPLA3 protein, indicating that the protein regulation was, at least partially, posttranslational. Further experiments with an acyl-CoA synthetase inhibitor confirmed that the regulation was likely due to direct effects of FA, not due to lipid accumulation.

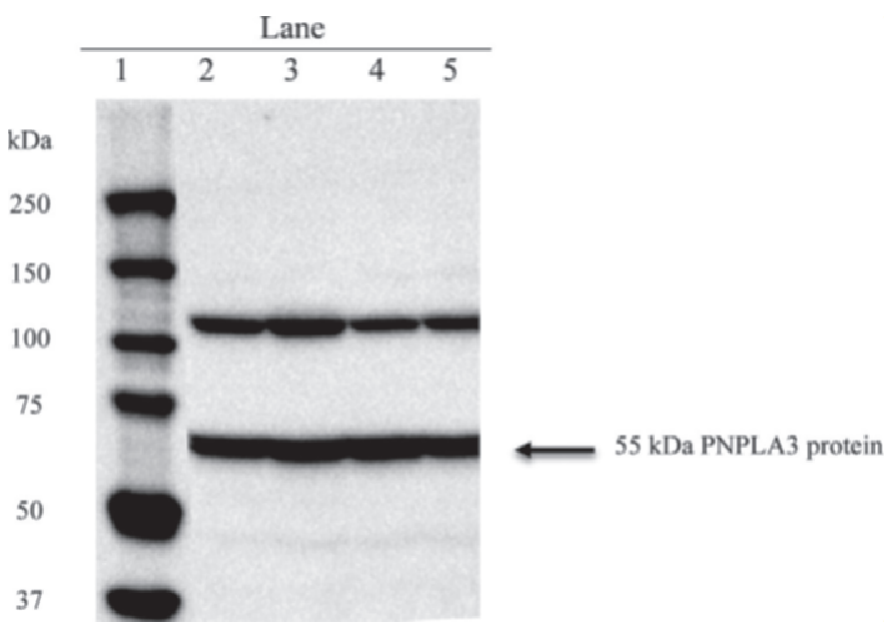

Figure 5. Representative Western blot validation of bovine patatinlike phospholipase domain-containing protein 3 protein (PNPLA3). Lanes 2 through 5 were loaded with $50 \mu \mathrm{g}$ of liver protein isolated from liver biopsy tissue collected from 4 cows at $+28 \mathrm{~d}$ relative to calving to identify bovine PNPLA3 protein. Lane 1 was loaded with a molecular weight marker. The PNPLA3 protein was expected at 55 $\mathrm{kDa}$, as observed; the additional band at approximately $120 \mathrm{kDa}$ is a high-molecular-weight product. 
Given the regulation of hepatic PNPLA3 by FA in rodents and human hepatocytes (Huang et al., 2010), it is possible that bovine PNPLA3 is also responsive to FA, which are known to be dynamic during changes in energy balance in ruminant animals. Circulating NEFA concentrations were increased in both the feedrestricted cows (White et al., 2011a) and during +1 and +14 DRTC (Carvalho et al., 2011), as reported previously. Expression of PNPLA3 mRNA in each animal was negatively correlated with plasma NEFA concentration, with a modest, although significant $\mathrm{r}$ value of -0.33 . Increased NEFA concentration during these physiological states is known to regulate other bovine hepatic genes (Bionaz et al., 2008; Thering et al., 2009; White et al., 2011b). Further research is necessary to determine if bovine PNPLA3 is responsive to changes in circulating FA associated with negative energy balance, or if the responsiveness of this gene to feed restriction and the transition to the lactation period is alternatively mediated.

Correlations between inactivating SNP in the human PNPLA3 gene and fatty liver disease (Rotman et al., 2010; Speliotes et al., 2010; Corbin et al., 2013) indicate that inactivating SNP may predispose individuals to disease onset and progression. The nonsynonymous coding SNP identified in the human PNPLA3 gene (rs738409) results in an Ile-to-Met substitution at residue 148 (PNPLA3-I148M) within the patatin-like domain, rendering the protein inactive (Romeo et al., 2008; Yuan et al., 2008). The presence of PNPLA3I148M increases liver triglyceride (TG) by limiting hepatic TG hydrolysis (He et al., 2010).

The strong relationship between SNP inactivation of PNPLA3 in humans and disease onset and progression, together with the high degree of homology between human and bovine PNPLA3, suggest that potential inactivating SNP in the bovine PNPLA3 gene may also alter protein activity. Four nonsynonymous PNPLA3 SNP identified in the current work lie within the coding region of the gene and may alter protein activity or stability. Although the nonsynonymous SNP do not lie within the patatin-like domain as the I148M human inactivating mutation does, an effect of AA mutation on protein abundance, stability, or activity may still exist. Glycine-to-serine mutations, such as the G374S and G406S mutations, have been demonstrated to alter formation and destabilize other proteins (Westerhausen et al., 1990; Bateman et al., 1992; Zhao et al., 2000). The effects of alanine-to-valine or arginine-to-tryptophan mutations are protein dependent, with some mutations inhibiting protein folding or disease risk (Imoto et al., 1987; Ponjavic et al., 1997) and other similar mutations being tolerated (Gregoret and Sauer, 1998; Sun et al., 1998). Protein products of these SNP need to be further examined to determine if the presence of SNP result in changes in protein abundance or activity. Furthermore, SNP presence needs to be determined in a larger data set, with hepatic phenotypes, to ascertain potential relationships between SNP presence, protein activity, and fatty liver disease.

The human and rodent PNPLA3 proteins are membrane-bound, lipolytic proteins present in hepatic tissue (Jenkins et al., 2004; Farrell, 2010); however, presence of bovine PNPLA3 protein in hepatic tissue has not previously been verified. Presence of bovine PNPLA3 protein in hepatic protein extracts was confirmed in the present work by Western blot. A $55-\mathrm{kDa}$ band representing the PNPLA3 protein (Figure 5) is similar to the human PNPLA3 protein (Abcam PLC). A high-molecular-weight product at approximately 120 $\mathrm{kDa}$ was observed in both the current bovine work and the previously validated use of this antibody with human protein (Abcam PLC).

In hepatocytes, PNPLA3 is involved in lipolysis of TG to release FFA (Browning et al., 2010; Rotman et al., 2010; Speliotes et al., 2010). As a result of the decrease in hepatic PNPLA3 mRNA expression, TG may accumulate in the liver rather than being liberated into FFA for oxidation, as is the case in the human inactivating SNP (I148M). In the fasted state, PNPLA3 expression is also decreased and liver lipid accumulation increases. It is possible that a decreased PNPLA3 protein abundance or activity, due to changes in mRNA expression or protein activity resulting from inactivating SNP, could predispose dairy cows to fatty liver disease by decreasing lipolysis in the liver by PNPLA3 and, therefore, increasing TG accumulation.

\section{CONCLUSIONS}

Patatin-like phospholipase domain-containing protein 3 plays a critical role in hepatic lipolysis in humans and rodents. The current work confirms the sequence and protein presence of bovine hepatic PNPLA3. Furthermore, examination of PNPLA3 after feed restriction and during the transition to the lactation period suggests that this gene is regulated during negative energy balance in dairy cattle. Further research is needed to determine potential effects of SNP within the bovine PNPLA3 gene and the specific mechanism of gene regulation; however, this research suggests that bovine PNPLA3 may play an important role in hepatic lipolysis in dairy cattle.

\section{REFERENCES}

Bateman, J. F., I. Moeller, M. Hannagan, D. Chan, and W. G. Cole. 1992. Characterization of three osteogenesis imperfecta collagen $\alpha 1(\mathrm{I})$ glycine to serine mutations demonstrating a position-dependent gradient of phenotypic severity. Biochem. J. 288:131-135. 
Bionaz, M., C. R. Baumrucker, E. Shirk, J. P. Vanden Heuvel, E. Block, and G. A. Varga. 2008. Short communication: Characterization of Madin-Darby bovine kidney cell line for peroxisome proliferator-activated receptors: Temporal response and sensitivity to fatty acids. J. Dairy Sci. 91:2808-2813.

Boujedidi, H., L. Bouchet-Delbos, A.-M. Cassard-Doulcier, M. NjikéNakseu, S. Maitre, S. Prévot, I. Dagher, H. Agostini, C. S. Voican, D. Emilie, G. Perlemuter, and S. Naveau. 2012. Housekeeping gene variability in the liver of alcoholic patients. Alcohol. Clin. Exp. Res. 36:258-266.

Browning, J. D., J. C. Cohen, and H. H. Hobbs. 2010. Patatin-like phospholipase domain-containing protein 3 and the pathogenesis and progression of pediatric nonalcoholic fatty liver disease. Hepatology 52:1189-1192.

Carvalho, E. R., N. S. Schmelz-Roberts, H. M. White, P. H. Doane, and S. S. Donkin. 2011. Replacing corn with glycerol in diets for transition dairy cows. J. Dairy Sci. 94:908-916.

Chen, W., B. Chang, L. Li, and L. Chan. 2010. Patatin-like phospholipase domain-containing 3/adiponutrin deficiency in mice is not associated with fatty liver disease. Hepatology 52:1134-1142.

Connor, E. E., S. Kahl, T. H. Elsasser, J. S. Parker, R. W. Li, C. P. Van Tassell, R. L. Baldwin VI, and S. M. Barao. 2010. Enhanced mitochondrial complex gene function and reduced liver size may mediate improved feed efficiency of beef cattle during compensatory growth. Funct. Integr. Genomics 10:39-51.

Corbin, K. D., M. F. Abdelmalek, M. D. Spencer, K.-A. da Costa, J. A. Galanko, W. Sha, A. Suzuki, C. D. Guy, D. M. Cardona, A Torquati, A. M. Diehl, and S. H. Zeisel. 2013. Genetic signatures in choline and 1-carbon metabolism are associated with the severity of hepatic steatosis. FASEB J. 27:1674-1689.

Farrell, G. C. 2010. PNPLeAse get the fats right: Does lipogenesis or lipolysis cause NASH? Hepatology 52:818-821.

Gregoret, L. M., and R. T. Sauer. 1998. Tolerance of a protein helix to multiple alanine and valine substitutions. Fold. Des. 3:119-126.

He, B., S. Zhao, W. Zhang, Y. Li, Y. Lu, and P. Han. 2010. Salicylate prevents hepatic oxidative stress activation caused by short-term elevation of free fatty acids in vivo. Diabetes Res. Clin. Pract. 89:150-156.

Hoekstra, M., Z. Li, J. K. Kruijt, M. Van Eck, T. J. C. Van Berkel, and J. Kuiper. 2010. The expression level of non-alcoholic fatty liver disease-related gene PNPLA3 in hepatocytes is highly influenced by hepatic lipid status. J. Hepatol. 52:244-251.

Huang, Y., S. He, J. Z. Li, Y.-K. Seo, T. F. Osborne, J. C. Cohen, and H. H. Hobbs. 2010. A feed-forward loop amplifies nutritional regulation of PNPLA3. Proc. Natl. Acad. Sci. USA 107:7892-7897.

Imoto, T., H. Yamada, T. Yasukochi, E. Yamada, Y. Ito, T. Ueda, H. Nagatani, T. Miki, and T. Horiuchi. 1987. Point mutation of alanine (31) to valine prohibits the folding of reduced lysozyme by sulfhydryl-disulfide interchange. Protein Eng. 1:333-338.

Jenkins, C. M., D. J. Mancuso, W. Yan, H. F. Sims, B. Gibson, and R. W. Gross. 2004. Identification, cloning, expression, and purification of three novel human calcium-independent phospholipase $\mathrm{A}_{2}$ family members possessing triacylglycerol lipase and acylglycerol transacylase activities. J. Biol. Chem. 279:48968-48975.

Ji, P., J. S. Osorio, J. K. Drackley, and J. J. Loor. 2012. Overfeeding a moderate energy diet prepartum does not impair bovine subcutaneous adipose tissue insulin signal transduction and induces marked changes in peripartal gene network expression. J. Dairy Sci. 95:4333-4351.

Johansson, L. E., J. Hoffstedt, H. Parikh, E. Carlsson, M. Wabitsch, A. Bondeson, J. Hedenbro, H. Tornqvist, L. Groop, and M. Ridderstråle. 2006. Variation in the adiponutrin gene influences its expression and associates with obesity. Diabetes 55:826-833.

Kershaw, E. E., J. K. Hamm, L. A. W. Verhagen, O. Peroni, M. Katic, and J. S. Flier. 2006. Adipose triglyceride lipase: Function, regulation by insulin, and comparison with adiponutrin. Diabetes $55: 148-157$.

Khan, M. J., C. B. Jacometo, D. E. Graugnard, M. N. Corrêa, E. Schmitt, F. Cardoso, and J. J. Loor. 2014. Overfeeding dairy cattle during late-pregnancy alters hepatic PPAR $\alpha$-regulated pathways including hepatokines: Impact on metabolism and peripheral insulin sensitivity. Gene Regul. Syst. Bio. 8:97-111.

Lake, A. C., Y. Sun, J.-L. Li, J. E. Kim, J. W. Johnson, D. Li, T. Revett, H. H. Shih, W. Liu, J. E. Paulsen, and R. E. Gimeno. 2005. Expression, regulation, and triglyceride hydrolase activity of adiponutrin family members. J. Lipid Res. 46:2477-2487.

Lardizábal, M. N., A. L. Nocito, S. M. Daniele, L. A. Ornella, J. F. Palatnik, and L. M. Veggi. 2012. Reference genes for real-time PCR quantification of microRNAs and messenger RNAs in mouse model of hepatotoxicity. PLoS ONE 7:e36323.

Liu, Y., M. Moldes, J.-P. Bastard, E. Bruckert, N. Viguerie, B. Hainque, A. Basdevant, D. Langin, J. Pairault, and K. Clément. 2004. Adiponutrin: A new gene regulated by energy balance in human adipose tissue. J. Clin. Endocrinol. Metab. 89:2684-2689.

Matoušková, P., H. Bártíková, I. Boušová, V. Hanušová, B. Szotáková, and L. Skálová. 2014. Reference genes for real-time PCR quantification of messenger RNAs and microRNAs in mouse model of obesity. PLoS ONE 9:e86033.

Moldes, M., G. Beauregard, M. Faraj, N. Peretti, P.-H. Ducluzeau, M. Laville, R. Rabasa-Lhoret, H. Vidal, and K. Clément. 2006. Adiponutrin gene is regulated by insulin and glucose in human adipose tissue. Eur. J. Endocrinol. 155:461-468.

NRC. 2001. Nutrient Requirements of Dairy Cattle. 7th rev. ed. Natl. Acad. Sci., Washington, DC.

Oliver, P., A. Caimari, R. Díaz-Rúa, and A. Palou. 2012. Diet-induced obesity affects expression of adiponutrin/PNPLA3 and adipose triglyceride lipase, two members of the same family. Int. J. Obes. (Lond.) 36:225-232.

Ponjavic, V., M. Abrahamson, S. Andréasson, B. Ehinger, and G. Fex. 1997. Autosomal dominant retinitis pigmentosa with a rhodopsin mutation (Arg-135-Trp). Disease phenotype in a Swedish family. Acta Ophthalmol. Scand. 75:218-223.

Romeo, S., J. Kozlitina, C. Xing, A. Pertsemlidis, D. Cox, L. A. Pennacchio, E. Boerwinkle, J. C. Cohen, and H. H. Hobbs. 2008. Genetic variation in PNPLA3 confers susceptibility to nonalcoholic fatty liver disease. Nat. Genet. 40:1461-1465.

Rotman, Y., C. Koh, J. M. Zmuda, D. E. Kleiner, and T. J. Liang., and the NASH CRN. 2010. The association of genetic variability in patatin-like phospholipase domain-containing protein 3 (PNPLA3) with histological severity of nonalcoholic fatty liver disease. Hepatology 52:894-903.

Speliotes, E. K., J. L. Butler, C. D. Palmer, and B. F. Voight., the GIANT consortium, the MIGen Consortium, the NASH CRN, and J. N. Hirschhorn. 2010. PNPLA3 variants specifically confer increased risk for histologic nonalcoholic fatty liver disease but not metabolic disease. Hepatology 52:904-912.

Sun, L., S. Ishibashi, J. Osuga, K. Harada, K. Ohashi, T. Gotoda, Y Fukuo, Y. Yazaki, and N. Yamada. 1998. Clinical features associated with the homozygous $\operatorname{Tr}^{64} \mathrm{Arg}$ mutation of the $\beta 3$-adrenergic receptor: No evidence for its association with obesity in Japanese. Arterioscler. Thromb. Vasc. Biol. 18:941-946.

Thering, B. J., M. Bionaz, and J. J. Loor. 2009. Long-chain fatty acid effects on peroxisome proliferator-activated receptor- $\alpha$-regulated genes in Madin-Darby bovine kidney cells: Optimization of culture conditions using palmitate. J. Dairy Sci. 92:2027-2037.

Westerhausen, A., J. Kishi, and D. J. Prockop. 1990. Mutations that substitute serine for glycine $\alpha 1-598$ and glycine $\alpha 1-631$ in type I procollagen. J. Biol. Chem. 265:13995-14000.

White, H. M., S. L. Koser, and S. S. Donkin. 2011a. Bovine pyruvate carboxylase $5^{\prime}$ untranslated region variant expression during transition to lactation and feed restriction in dairy cows. J. Anim. Sci. 89:1881-1892.

White, H. M., S. L. Koser, and S. S. Donkin. 2011b. Differential regulation of bovine pyruvate carboxylase promoters by fatty acids and peroxisome proliferator-activated receptor- $\alpha$ agonist. J. Dairy Sci. 94:3428-3436.

White, H. M., S. L. Koser, and S. S. Donkin. 2012. Gluconeogenic enzymes are differentially regulated by fatty acid cocktails in MadinDarby bovine kidney cells. J. Dairy Sci. 95:1249-1256.

Yuan, X., D. Waterworth, J. R. B. Perry, N. Lim, K. Song, J. C. Chambers, W. Zhang, P. Vollenwelder, H. Stirnadel, T. John- 
son, S. Bergmann, N. D. Beckmann, Y. Li, L. Ferrucci, D. Melzer, D. Hernandez, A. Singleton, J. Scott, P. Elliott, G. Waeber, L. Cardon, T. M. Frayling, J. S. Kooner, and V. Mooser. 2008. Population-based genome-wide association studies reveal six loci influencing plasma levels of liver enzymes. Am. J. Hum. Genet. $83: 520-528$.

Zhao, D., H. M. Hutton, T. E. Meyer, F. A. Walker, N. E. MacKenzie, and M. A. Cusanovich. 2000. Structure and stability effects of the mutation of glycine 34 to serine in Rhodobacter capsulatus cytochrome $c_{2}$. Biochemistry 39:4053-4061.

Zimin, A. V., A. L. Delcher, L. Florea, D. R. Kelley, M. C. Schatz, D. Puiu, F. Hanrahan, G. Pertea, C. P. Van Tassell, T. S. Sonstegard, G. Marçais, M. Roberts, P. Subramanian, J. A. Yorke, and S. L. Salzberg. 2009. A whole-genome assembly of the domestic cow, Bos taurus. Genome Biol. 10:R42. 